\title{
A Process to Analyze Ethical Issues of Information Systems
}

\author{
Flavia Maria Santoro, Rosa Maria E. Moreira da Costa
}

\author{
Instituto de Matemática e Estatística, Universidade do Estado do Rio de Janeiro (UERJ) \\ - Rio de Janeiro, RJ, Brazil \\ \{flavia, rcosta\}@ime.uerj.br
}

\begin{abstract}
Contemporary society is going through the so-called Digital Age. In this scenario, information systems (IS) play an essential role in many sectors of society, such as commerce, politics, services, entertainment, information sharing. Although discussions about ethical issues become increasingly necessary, it is not always an easy task. This paper proposes a process to help the IS professional and the citizen in sensitive decision-making contexts, in which conflicts may arise. To justify the definition of this process, we discussed the importance of new technologies based on Andrew Feenberg's philosophy of technology. Finally, we analyze the results of its application in the context of a well-known case in the light of the theoretical foundations.
\end{abstract}

Resumo. A sociedade contemporânea está passando pela chamada Era Digital. Nesse cenário, os sistemas de informação (SI) desempenham um papel essencial em muitos setores da sociedade, como comércio, política, serviços, entretenimento, compartilhamento de informações. Apesar da discussão ética se tornar cada vez mais necessária, nem sempre é uma tarefa fácil. Este artigo adapta um processo existente para ajudar o profissional de SI e o cidadão em contextos de tomada de decisão, nos quais conflitos podem aparecer. Para justificar a definição desse processo, discutimos a importância das novas tecnologias com base na filosofia da tecnologia de Andrew Feenberg. Por fim, analisamos os resultados da aplicação deste processo em um caso bem conhecido à luz dos fundamentos teóricos.

\section{Introduction}

Contemporary society is living the so-called Digital Era. In this scenario, Information Systems (IS) plays an essential role shaping many segments, such as, commerce, politics, services, entertainment, information sharing. Our social relationships are being increasingly influenced by the internet, cell phone, digital television, etc., but we face both positive and negative impacts. Whether these features at the same time offer attractive possibilities, on the other hand, they also contribute to progressively promote more virtual relationships. Through the Internet, with the support of mobile devices, we have been able to communicate much more easily with many people and we have access to a multitude of information, but often this comes accompanied by the invasion of privacy and information overload that we cannot understand, or with a feeling of total dependence on these resources.

Computer technology is genuinely revolutionary because it is "logically malleable" as computers can be programmed to perform any activity characterized in terms of inputs, outputs, and logic operations (Moor, 1985). Since logic applies to 
everything, the possible functions of computational technology seem to be unlimited. According to Moor (1985), the computer revolution occurs in two stages: the first one is the technological introduction, in which computational technology is developed and refined, and this has already occurred in the first 40 years after the Second World War; and the second one is the technological permeation in which technology integrates into everyday human activities and social institutions, changing the actual meaning of traditional institutions such as money, education, work or democracy. Thus, a particular ethical discussion is applicable.

Moor (1985) proposes a broad and comprehensive definition of Computational Ethics, which is independent of a specific philosophical theory and at the same time compatible with a wide variety of approaches to solving ethical problems. For the author, there is a political gap in how Computational Ethics should be used. Computing gives us novel features, and these, in turn, give us new opportunities for action. Often there are no policy in these situations, or the existing policies seem inappropriate. Focusing on Information Systems (IS), a central task would be to determine what we should do in those cases, i.e., to formulate strategies to guide our actions. Another difficulty is that, although a problem in Information Systems Ethics may initially seem clear, a deeper understanding may reveal a conceptual conflict. Such cases require analyses able to provide a coherent conceptual framework within which it would be possible to formulate an action policy.

This paper proposes that situations involving both the design and the adoption or use of IS should be analyzed from the point of view of Ethics through a well-defined process that helps the professional or the citizen in making decisions in sensitive contexts when conceptual conflicts show up. To justify the definition of this process, we discuss the significance of the new technologies based on Andrew Feenberg's philosophy of technology (Dusek, 2006). Having done this, we highlight the benefits and problems of the new technologies in the contemporary world. Finally, we present the process proposal and analyze the results of its application in the context of a real case in light of the theoretical foundation.

\section{The Meaning of New Technologies}

Nowadays, it is very difficult to think of humankind without technology. Technology takes part in determining our evolution as humans. However, what is the meaning that we give to technology in our life? Is the importance of a specific technology associated with the significance we give to it?

Feenberg (2013) explains that there is an important distinction related to what the Greeks called physis and poiesis. Physis is translated as nature. The Greeks understood nature as something that emerges from itself. Poiesis is the activity of making, occurs when men produce something, so-called artifacts; everything from art, crafts, to social contracts. The word techne, the origin of the modern words "technique" and "technology", means the knowledge or discipline associated with a form of poiesis. For the Greeks, each techne guides the production of an artifact, associating it with purpose and meaning. Although artifacts depend on human activity, the knowledge contained in techne is not subject to opinion or intention. So, the purpose of artifacts also shares objectivity since they are defined by techne. 
Another important distinction is between existence and essence. According to Feenberg (2013), existence answers the question of whether something is or is not; yet, the essence answers the question what the thing is. The essence of natural things includes a purpose, and as well the essence of artifacts does. Therefore, humans are not the heads of nature, but they work with their potential to bring forth a meaningful world. Knowledge about the world and human action in it are not arbitrary, but the realization of what is hidden in nature. Feenberg (2013) concludes that the Greeks interpreted the being as such through the concept of technical fabrication. Technology occupies an inferior position in the high culture of modern societies, but it was, in fact, already at the origin of this culture and, according to the Greeks, it holds the key to the understanding of being as a whole.

René Descartes and Francis Bacon, the founders of modern thought, changed this scenario: Descartes stated that, through science, man is master of nature, and Bacon claimed that "knowledge is power". The meaning and ends of things are something that man creates and not what he/she discovers. In the modern era, technology was understood as purely instrumental and value-free. The instrumentalist philosophy of technology prevails as product of civilization, unwittingly assumed by most people. Technology, in this context, treated nature as raw material to be controlled and used. In the $19^{\text {th }}$ century, the modernity comes with progress toward the satisfaction of human needs towards technological advancement. For Feenberg (2013), the question that arises is "for what purposes?" The author states that this issue brought about a crisis of civilization to which there is no way out: "we know how to get there, but we do not know why we are going, or even to where". So, it was not clear what damage was attributed to the technology. But in the $20^{\text {th }}$ century, with world wars and environmental catastrophes, it was no longer possible to ignore the lack of meaning of modernity.

Feenberg (2013) organized the lines of thinking about technology and summarized those views, according to Table 1. The author classifies the technology through two axes that reflect the relationship with human value, and control. The vertical axis presents either technology value as neutral, as the Illuminism assumed, or technology with value-added, as the Greeks thought. On the horizontal axis, the technology is considered autonomous or humanly controllable. Autonomous technology does not mean that it works by itself; the human being is involved, but the question is whether they have, in fact, the freedom to decide how the technology will be developed. On the other hand, technology can be humanly controllable, while the next step of evolution can be determined according to our intentions. Four quadrants stand out.

Table 1 - Lines of Thought about Technology (Feenberg, 2013)

\begin{tabular}{|l|l|l|}
\hline Technology is ... & Autonomous & Human-controlled \\
\hline $\begin{array}{l}\text { Neutral } \\
\begin{array}{l}\text { Separation between means and } \\
\text { ends, reference to Iluminism }\end{array}\end{array}$ & $\begin{array}{l}\text { Determinism } \\
\text { For example, theory of } \\
\text { modernization }\end{array}$ & $\begin{array}{l}\text { Instrumentalism } \\
\text { Liberal faith in progress }\end{array}$ \\
\hline $\begin{array}{l}\text { Value-added } \\
\begin{array}{l}\text { Means form a way of life that } \\
\text { include ends, reference to Greek } \\
\text { though }\end{array}\end{array}$ & $\begin{array}{l}\text { Substantivism } \\
\text { Means and end connected to } \\
\text { systems }\end{array}$ & $\begin{array}{l}\text { Critical Theory } \\
\text { Choice for alternative means-end } \\
\text { systems }\end{array}$ \\
\hline
\end{tabular}

We can attribute meaning to technology under different theoretical frameworks. Additionally, there will always be counterpoints between the benefits that a technology can potentially bring to society and the harm it can cause. Following, we discuss the 
advantages and disadvantages of three important contemporary technologies that have been permeating many aspects of our daily life, and moreover, are shaping the near future a society: Internet, Artificial Intelligence and Big Data.

\subsection{Digital Society: The Rise of Internet and its Social Networks}

The Internet is one of the most important technologies of the so-called "Information Age" or "Digital Society". Great sociocultural changes are observed in terms of work environment, family, entertainment and leisure. Individuals, companies, and institutions, in general, perceive these changes at times as utopias, and others as dystopias. For example, social networking is currently the preferred platforms for all sorts of activities, both for business and personal, and sociability has greatly increased. It is clear the migration of businesses (electronic businesses), government (electronic government) and civil society in general to social networks. Moreover, relevant political movements have started from social networks, for example in Arab revolutions against dictatorships and protests against the management of the financial crisis. There are innumerable benefits of the Internet, such as access to information, new business models, increased communication possibilities, tools to support learning, among many others.

The democratization of access to information has never been more publicized and promoted than in the Internet era, and the most frequent propaganda is about individual freedom as far as content is supposed to be "personalized". However, this is not totally true, despite the undeniable utopian potential of integration, connectivity and mobilization of people, as well as the availability of a space for political activity, as pointed out by Adorno and Horkheimer (1985) in the case of the Cultural Industry. Social networks are formed by autonomous participants, who expose ideas and personal assets with the purpose of sharing values and interests. Diversity and the massive public allow each user to publish any type of information without commitment with the truth.

According to Siegel (2008), supporters of cyberculture (like Lévy, 1999) argue that we are entering the era of demassification because we would be able to make our own choices and build our personality freely. But Siegel (2008) states that what it is being created is an even more potent form of homogenization. This author affirms that it is a fallacy that we are moving from passive recipients to becoming independent content producers, just because we can now share our ideas and images with people through the new media in Social Networks. People are making their own private moments accessible on social media.

On Social Networks, people produce mostly "images", which are copies of information in various formats, manipulated by applications that distort its original appearance (for example, a text or an edited picture/photo, a video clipped without the credits) (Santoro, 2017). The problem is not the manipulation itself, but the fact that the information is "sold" as original. The viral propagation of such images causes their new meaning to be taken as fact, meanwhile, the original facts associated with them become lost. The "truth" does not seem to be a tonic in the networks; people tend to talk about what make them more popular and assume positions guided by the recommendations of the systems. Social Networks usually deliver an overflow of recommendations. All the time people spend interacting with each other and with systems over the Internet, they are simultaneously providing information about their profile. Targeted information sets the minds of potential consumers not only with products but with ideas and ways of acting and thinking. Advertising is increasingly tangled with information. The social 
networks offer suggestions of what your best moments in the past were, who your best friends are, and can associate your profile with animals, games, music, etc. In addition, it can emphatically suggest the form of joining a protest or become supportive with a social problem, according to the design previously made and offered to citizens.

The application of statistics and computational techniques of classification has reached a very high degree of sophistication, endorsing a sense of belonging (or nonbelonging) of a person to certain groups. The next step is the recommendation of consumption (Kohn and Moraes, 2007). Then the cycle closes. According to Rüdiger (2011), the danger of the cyberspace is to promote an abandonment of concerns with physical reality: lost in the hybrid and strange world of the network, we may believe that virtual homes are real, that a reported clash is not different than a real one, that virtual sex is no less viable than the thing itself (Slouka, 1995). The inhabitant of the cities can only know the friendship in the Social Networks. Thus, the strong impact of the Internet and particularly of social networks seems to be that technology is blurred with the way of life and it can apprehend the human being better than himself/herself.

\subsection{The Spread of Artificial Intelligence}

Artificial intelligence (AI) is a research field whose focus is the development of computational methods and artifacts that possess or multiply the rational capacity of human beings to solve problems, to think or, in general, to be "intelligent". But what exactly do we call "artificial intelligence"? We separate it into two parts: "artificial" and "intelligence". The first one is related to what man can construct, i.e., the artifacts. The second one refers to concepts such as consciousness, identity, and mind. Consciousness is one of the most complex mental processes which we judge to be the human's differential. Consciousness is the state of being conscious; the perception of oneself, his/her thoughts and what exists around him/her.

The growth of AI began shortly after World War II with the article "Computing Machinery and Intelligence" by the famous English mathematician Alan Turing, and the name 'Artificial Intelligence' was coined in 1956 (Berkeley, 1997). However, this idea is not recent. Aristotle, the Greek philosopher born in $384 \mathrm{BC}$, already thought of replacing the slave labor force with autonomous objects. The development of this proposal began to take shape in the 1950s, with the scholars Herbert Simon and John McCarthy. Since then, the foundations of AI have been supported by diverse disciplines, such as Philosophy, Mathematics, Economics, Psychology, and Linguistics, which have contributed with ideas and techniques. Only recently, the emergence of the modern computer made AI gains critical mass and tools to establish itself and advance in areas such as computer vision, speech analysis and synthesis, fuzzy logic, artificial neural networks, and many others.

Nevertheless, we observe several negative issues related to AI, such as unemployment generated by the substitution of labor by autonomous machines; inequality caused by the poor distribution of the wealth generated by the machines; changes in human behavior and interpersonal relationships; possible mistakes made by autonomous machines, some of which may be fatal to humans; risks of autonomous weapons; uncertainty that AI may one day surpass human capabilities and intelligence; hesitation about the interaction between humans and robots. 
According to Sofia Miguens ${ }^{1}$, philosophers have been taking extreme positions about AI. Some of them argue for an impossibility, by principle, of creating unnatural intelligence and consciousness. Others are convinced that AI could create a more general and abstract concept of the nature of intelligence, which places humans and all intelligent biological beings as only particular cases of a general phenomenon. Basically, if any system with the right kind of functional organization can be intelligent, and even conscious, and whether this condition can be formulated independently of the substance that constitutes it and its origins, then those systems may be intelligent and conscious as well. In 2015, the physicist Stephen Hawking, and entrepreneurs Elon Musk (founder of Tesla and SpaceX), Steve Wozniak (Apple co-founder) and Bill Gates (co-founder of Microsoft) signed an open letter with concerns about artificial intelligence. The letter is not intended to deny the development of research in the field of AI, but it draws attention to the dangers of developing something so powerful and promising without also paying attention to the generation of benefits for humanity and intrinsic ethical issues.

\subsection{Big Data $X$ Big Brother}

The term Big Data is usually associated with a large set of stored data. From the technical point of view, the challenges of this area include analysis, capture, repository creation, and development for this data, research, sharing, storage, transfer, and visualization (Chen and Zhang, 2014). But some particular characteristics differentiate this data from any other else. They are called the 5 V's: velocity, volume, variety, veracity, and value. Big Data is a recent term, but the idea is quite old. By $3500 \mathrm{BC}$, the bureaucrats of ancient Mesopotamia created writing, because they had to register and maintain control of commercial transactions. Mayer-Schonberger and Cukier (2013) argue that the invention of written language allowed early civilizations to record facts about reality to be retrieved later. This was the embryo of tailoring a phenomenon to a quantified format so that it can be tabulated and analyzed.

Wu et al. (2013) argue that according to an IBM survey, 2.5 billion bytes of data are created every day and 90 percent of the data in the current world was produced in the past two years. Our data-generating capacity has never been so powerful. One example is Instagram, purchased by Facebook in 2012. More than 95 million photos and videos are shared on Instagram per day. Assuming the size of each photo is 2 megabytes (MB), it results in several terabytes (TB) of air-storage every day. Since "a picture is worth a thousand words", the billions of Instagram photos are a treasure for us to explore human society, social events, public affairs, disasters, etc., but only with the processing of this amount of data, exploring complex relationships and data evolution, which come from large heterogeneous autonomous sources with distributed and decentralized control (Wu et al., 2013).

Chen and Zhang (2014) point out that there is no doubt that future advances in productivity and business technologies will converge on Big Data's assets. Currently, more and more areas involve Big Data problems, ranging from the global economy to society administration, and scientific research to national security. Big Data has a deep relationship with e-Science, which is computer-intensive science, which is generally implemented in distributed computing systems. E-Sciences include particle physics,

\footnotetext{
${ }^{1}$ http://filocinetica.blogspot.com.br/2010/12/inteligencia-artificial-e-filosofia.html
} 
bioinformatics, earth science, and social simulations. The benefits of Big Data applications in society have already been understood, but what are the "problems" or points of attention with this promising technology? Mayer-Schönberger and Cukier (2013) warn that when data is collected passively, while people do what they normally do anyway, the old biases associated with sampling seem to disappear. Now we can collect information we could not do before, be it relationships revealed through mobile phone calls or feelings revealed through tweets.

\section{Proposal: Analyzing Ethical Issues}

As we discussed in the previous sections, considering the benefits and threats of using any new technology to develop and use IS, it is not easy to take part in ethical discussions. Landon and Landon (2011) suggested steps on how to discuss the ethical issues in IS, which can be very useful in practice: identify and clearly describe the facts; define the conflicts or dilemma and identify the values involved; identify stakeholders; identify reasonable alternatives to be adopted; and identify potential consequences of the options. We extended this proposal, detailing how each step could be performed, and furthermore, we also included two more steps. The steps are described in detail as follows. Our main goal is to support decision making as well as to promote group discussions. Thus, we propose this process to organize ideas, analyze and decide about an ethical issue related to the use and adoption of IS. Figure 1 shows the process formally represented in a BPMN ${ }^{2}$ (Business Process Modeling and Notation) diagram.

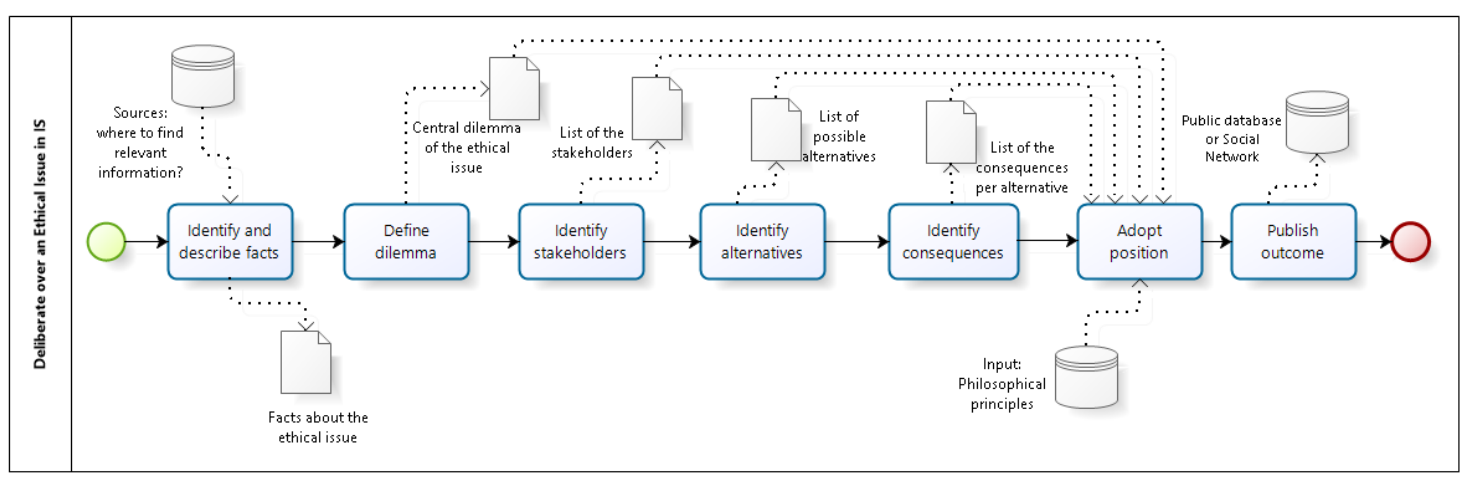

Figure 1 - A process for deliberation on ethical issues

A.Identify and clearly describe the facts: The right view of a situation might help to find a solution. So, the first step is looking for safe sources that help find out who did what, when and how.

B.Define dilemma: After understanding the facts, it is critical to recognize the conflicts or dilemma and identify the values involved: an ethical issue encompasses opposing directions of action concerning important values (e.g., freedom, privacy, property protection, etc.)

C.Identify stakeholders: In order to classify the likely interests on the issue, this step suggests generating a list of stakeholders. Stakeholders might be associated with

\footnotetext{
${ }^{2}$ http://www.bpmn.org/
} 
different groups of the society, for example, citizens; educational institutions; industry. However, a stakeholder could also be an individual: the owner of a company; a designer; a student, etc.

D.Identify alternatives: Alternatives are different implementations that might address the problem. Since we are discussing problems related to IS adoption or use, alternatives are different designs of the IS or the diverse adoption processes of the IS. This step identifies reasonable alternatives to be followed (which will not always satisfy all stakeholders' requirements).

E.Identify consequences: Each alternative implies in consequences. Identify potential consequences of the options (listed in the previous step) is asking yourself what would happen over time with each of the alternatives listed.

F.Adopt position: The conclusion of a deliberation on an ethical issue should use all the elements collected and produced in previous steps and finally decide to adopt a position. At this point, it is necessary to take as base one or more philosophical principle. In the philosophical sphere, principles, while governed by moral laws, are values that the individual considers adopting according to what his/her conscience says. Some examples are: Idealism, Realism, Pragmatism.

G.Publish the outcome: Sharing both the discussion and the outcome with diverse groups of society is vital for promoting changes. Thus, the whole process should be published in a repository or in Social Networks. This will also allow to collect and compare decisions to support the definition of public policies.

\section{Application Scenario}

In this section, we discuss the proposed process in a real case. This case occurred in the United States and was widely publicized in the media, as well as presented in documentary and movies. Through this case, we show how to use the process in a debate over one of the most controversial contemporary themes: Privacy vs. Security, from the point of view of ethics related to the information systems.

When Edward Snowden ${ }^{3}$, a former collaborator of the National Security Agency (NSA) in the US, disclosed a confidential mass monitoring program, the people asked: "Is he a patriot or a traitor?", which leads immediately to the following question: "What is most important for society: security or privacy?" The answer to the first question depends on the value people give to civil disobedience. The answer to the second one depends on how this value system weighs security versus privacy. This is no doubt an ethical problem. But the further revelations also raised a question about ethics for which the answer may be more direct: "Should the government use telephone records to spy on millions of Americans and lie about it?" Or, in other words, "How transparent should the US national security state be?" For sure, this is valid for any other country.

At that point, the fact that the United States has been operating monitoring and surveillance systems for electronic communications around the world became public. Global surveillance programs have several goals and capabilities, including intercepting communications by email, voice, video, facsimile, and any other means of communication anywhere in the world. Since then, the revelations have become more

\footnotetext{
${ }^{3}$ https://pt.wikipedia.org/wiki/Edward_Snowden
} 
alarming every day and have provoked a reaction in every country in the world and in the Internet protection experts' community. They range from participating in surveillance programs of companies such as Google, Facebook, Microsoft, to the worldwide invasion of computers (in the same way that the hackers do) and breaking the Internet's encryption codes, making the whole network vulnerable to the attacks both by the NSA or predators and criminals.

The US government argued that this data refers exclusively to the metadata of telephone calls, not the content of the calls themselves. Metadata resembles the "envelope" of a phone call or an email but contains more detailed information than just the recipient and sender with their addresses. This metadata contains the detailed information about the communication, be it email, phone call, or text message. However, metadata informs in detail, for example, destination, the duration of a call, date, location of the origin from where it was started the communication, location of the user that initiated and the recipient, type of computer or telephone used, etc. After the first publications in the press, technology experts and civil rights advocates right away warned that the White House underestimated the importance of metadata, but it actually contains detailed information about the individuals' lives, and it could be used to broadly draw relationships profiles and personal activities. We applied the process proposed in Section 3 to analyze the ethical issue in this case. The summary is presented in the following.

\section{A.Identify and clearly describe the facts:}

The sources of fact-finding in this case are newspapers and magazines (such as The Guardian, New York Times, etc.) and trusted Internet sites (e.g., Wikipedia).

Identified facts:

-Edward Snowden was an NSA employee.

-Edward Snowden released a confidential mass monitoring program, which was confirmed by the agency.

-The program intercepts people's communications by e-mail, voice, video, facsimile and any other means of communication anywhere in the world and collects data about them.

-The program uses techniques such as computer intrusion, breaking security codes, etc.

-The program uses tools that interpret this data to determine profiles.

-The purpose of the program is to ensure safety, but nothing prevents it from being used for other purposes.

\section{B.Define dilemma:}

The central dilemma (or ethical question) posed in this case can be defined as: Should the technology be applied to break the privacy of citizens in order to provide them with protection?

C.Identify stakeholders:

The stakeholders in this case are citizen, US government, former NSA service provider (IS professional), technology companies, society in general.

D.Identify alternatives:

How to solve this case? The alternative actions (not exhaustive) would be:

[1]Nothing to do, allow the government or any company to carry out these programs.

[2]Prohibit this type of program.

[3]Allow the program, but in a transparent way to the citizen.

[4]Create a new program that has access to data already available in traditional systems only.

E.Identify consequences:

For each possible action, the consequences (not exhaustive) would be:

[1]Nothing to do, allow the government or any company to carry out these programs. -Tolerate misuse of private information. 


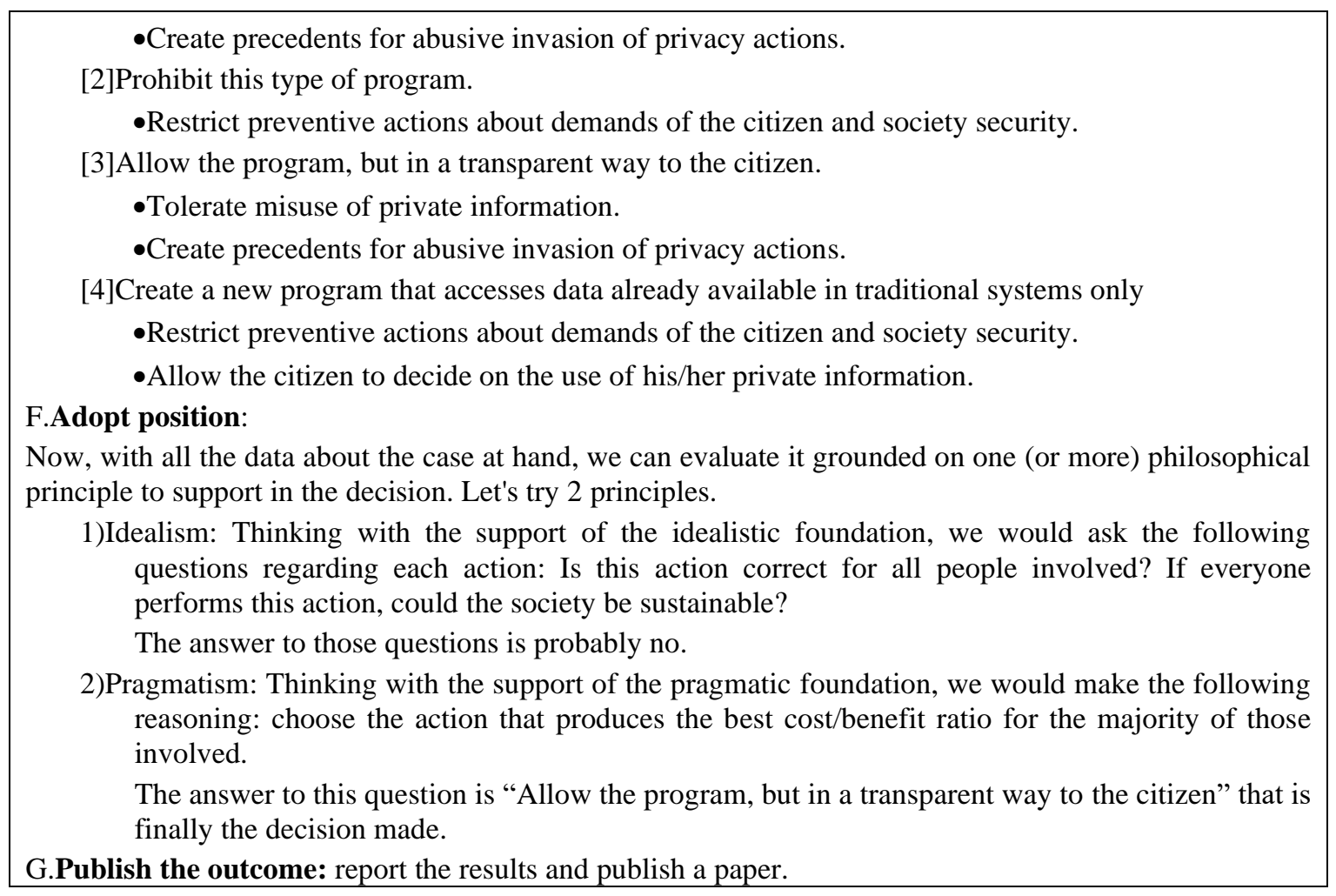

\section{Discussion: Towards a Critical Theory of IS}

In the previous sections, we underlined some of the most relevant contemporary technologies and the ways they affect our society and proposed a process to examine ethical issues. In the end, the general question is: "Do artifacts have underlying politics?"; "Do artifacts imply a certain organization of power and authority?" Mumford (1963) emphasized that the technical activity innate in human life was gradually subordinated to social and political devices, products of the subjection of the masses to the power of the elites. The philosophers of the Frankfurt School (Horkheimer, 1982) criticized the way in which industrial society with scientific and technological bases constitutes a broad system of domination of man by man. Levy (2001) has already warned that there is no computing in general, but rather an open, conflictive and partly indeterminate field of new technologies. Managers and engineers recognize that winning strategies bear minimal technical details but are primarily political and cultural.

Accordingly, we wonder whether the only form of rigorous and useful reasoning is the scientific and technological, or if there may be non-technical forms of reasoning applicable to social issues and day-to-day problems. Is it possible for the ordinary man, who does not participate in its design, to decide and have control over the technology? Our proposed process aims to be a starting point for this debate.

Feenberg (2013) proposes a Critical Theory of Technology and argues that technology is controllable, and it embeds value. Technology can shape many possible different lifestyles, reflecting choices of goals and mediation. For this author, the values embodied in a technology are characteristic of a society. Modern societies aim for efficiency; however, we cannot neglect other significant values besides it. Feenberg explains that it is impossible not to differentiate efficient weapons from efficient medicines, efficient propaganda from efficient education, efficient exploration from 
efficient research. The Critical Theory of Technology allows to think about choices and submit them to democratic controls. The Critical Technology Theory considers technology as an environment rather than a collection of tools. As an environment, technologies shape the lives of its inhabitants, being comparable to laws and rights. Thus, the systematization of ethical discussion would allow the citizens to engage in the decisions not only about what is wrong/right but how technology should be designed.

The main form of power has become the technological. Technological decisions are made according to the efficiency criterion, which in turn can be defined in diverse ways according to social interests. Feenberg identifies a social "code" of technology that blends efficiency and purpose, and, somehow legislates in our lives. Our way of life and our own gestures are programmed by artifacts with rigidity unprecedented in premodern societies (Feenberg, 2009). Feenberg calls technical codes the social principles embedded in a technology that is successful and enduring. Specific technical codes determine the meaning of particular artifacts and in any situation describe the congruence of a social demand and a technical specification.

A progressing society increases people's capacity to take political responsibility, fosters universality of the human being, allows for freedom of thought, respects the individual and encourages creativity Feenberg also cites concrete measures for this: the democratization of public administration, the extension of the lifespan devoted to learning beyond the immediate needs of the economy, and the evolution of professional training to include an ever-increasing range of human needs in the technician code.

The various aspects of design must be decided with respect to social principles and demands. This context must be widely understood to bring to technology into the public sphere, where increasingly it seems to belong. In Feenberg's proposal (2013), modern societies will only be able to realize democratic values when the public control of technology becomes routine. The Critical Theory of Technology projects a future in which technology policy is recognized as a normal aspect of public life. The design of technologies would be consciously oriented to politically legitimized human values, as opposed to the profit intentions of military organizations or bureaucracies. These values should be present in the technical disciplines themselves, just as the value of healing guides Medicine and knowledge of the human body guides Biology.

Our proposal corroborates with that principle. The outcome of the process to analyze an ethical issue allows the definition of politics of IS use and furthermore could guide the specification of the IS requirements. When people decide that transparency is a goal, it should be a requirement of the system to be developed.

\section{Conclusions}

Information systems should have an increasingly incisive presence in everyday activities. Argumentation on the impacts of new technologies requires theoretical and technical references. It will be up to the IS designer to intermediate the adaptation of the technology to the specificities of the diverse socio-cultural contexts. Thus, we conclude by emphasizing the fundamental role and responsibility of the designer in all these processes, for when designing new products and functionalities based on technologies such as the ones analyzed in this paper: internet, artificial intelligence, big data, or other new technologies to be developed in the future, he/she must be attentive to the so-called "technical code", as pointed out by Feenberg. 
We proposed a process to address ethical discussions about IS. The steps of this process guide the individual to take a decision. The main contribution of this paper is the argumentation on how a process like the one proposed could support the implementation of a Critical Theory of Information Systems, as argued by Feenberg, engaging people on the dialogue about IS requirements that shape the society in which he/she is inserted. Future work includes the evaluation of the method proposed with different groups of people and contexts. Besides, we intend to implement a tool to support the method and make it available and public in order to encourage the emergence of other relevant ethical questions.

\section{References}

Adorno, T. W., Horkheimer, M. (2002). "Dialectic of Enlightenment”, Trans. Edmund Jephcott, Stanford: Stanford UP.

Bunge, M. (1968). Scientific laws and rules. Contemporary philosophy: a survey. Florence: La Nuova Italia Editrice, v.2.

Chen, C.L.P., Zhang, C.Y. (2014). Data-intensive applications, challenges, techniques and technologies: A survey on Big Data. Information Sciences, 275: 314-347, 2014.

Dusek, V. 2006. "Philosophy of Technology: An Introduction", Malden, USA: Blackwell Publishing.

Feenberg, A. (2009). "Democratic Rationalization: Technology, Power and Freedom", Chap.10 (pp: 139-154). Readings in the Philosophy of Technology. Ed. Kaplan, David M. 2nd Ed. Plymouth: Rowman \& Littlefield Publishers Inc.

Feenberg, A. (2013) Critical Theory of Technology. A Companion to the Philosophy of Technology, Part III, Chapter 24. Edited by Jan Kyrre Berg Olsen, Stig Andur Pedersen, Vincent F. Hendricks, Malden: Blackwell Publishing.

Horkheimer, M. (1982). "Critical Theory Selected Essays”, New York: Continuum Pub.

Kohn, K., Moraes, C.H. (2007). O impacto das novas tecnologias na sociedade: conceitos e características da Sociedade da Informação e da Sociedade Digital. XXX Congresso Brasileiro de Ciências da Comunicação, Santos, 2007.

Levy, P. (2001). Cyberculture. University of Minnesota Press.

Mayer-Schönberger V, Cukier K. (2013). Big Data: A Revolution That Will Transform How We Live, Work, and Think. Boston, MA: Houghton Mifflin Harcourt.

Mumford, L. (1970). The myth of the machine. New York, H.B. Jovanovich, 2 vols.

Rüdiger, F. (2011). Cultura e cibercultura: princípios para uma reflexão conceitual crítica. Logos (UERJ) 34 (42-61) (in Portuguese).

Santoro, F.M. (2017) Information Technology in the Internet Era: Critical Theory Perspective. In: 23rd Americas Conference on Information Systems, Boston.

Siegel, L. (2008). Against the machine. Nova York: Spiegel \& Grau.

Slouka, M. (1995). War of the worlds. Nova York: Basic Books.

Wu, X., Zhu, X., Wu, G.Q, Ding, W. (2013). Data mining with big data. IEEE Transactions on Knowledge \& Data Engineering, vol. 26, no. 1, pp. 97-107. 